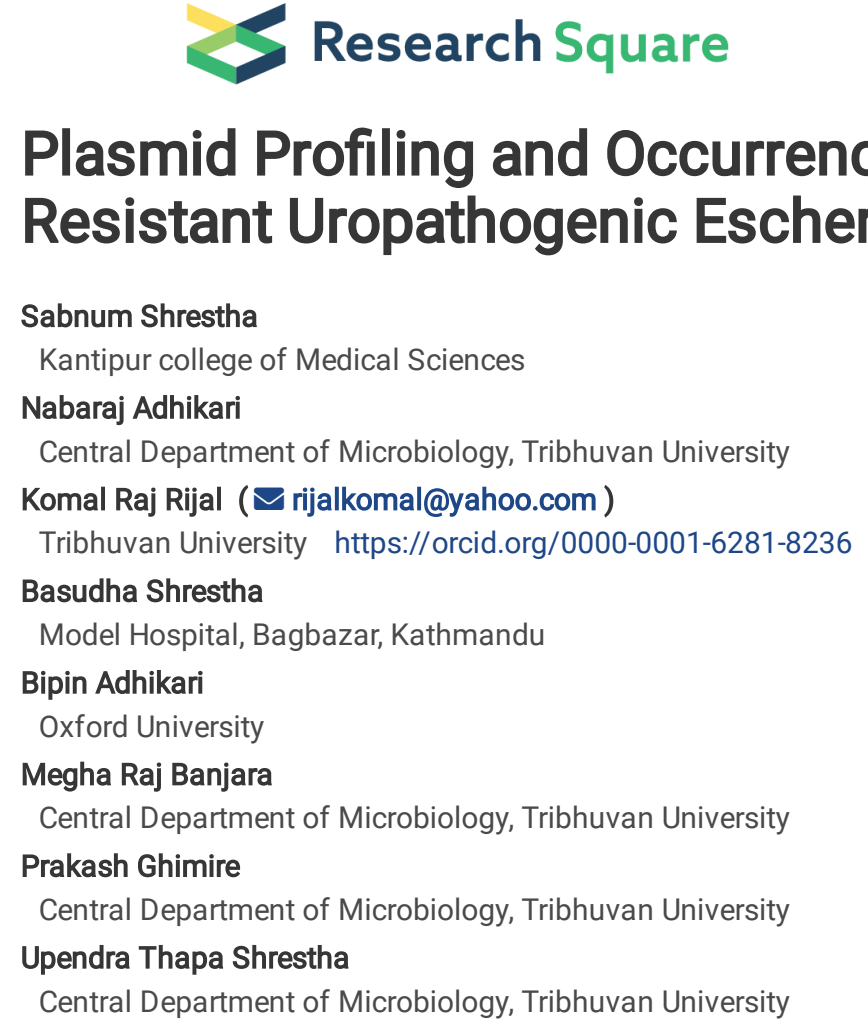

\author{
Sabnum Shrestha \\ Kantipur college of Medical Sciences \\ Nabaraj Adhikari \\ Central Department of Microbiology, Tribhuvan University \\ Komal Raj Rijal ( $\square$ rijalkomal@yahoo.com ) \\ Tribhuvan University https://orcid.org/0000-0001-6281-8236 \\ Basudha Shrestha \\ Model Hospital, Bagbazar, Kathmandu \\ Bipin Adhikari \\ Oxford University \\ Megha Raj Banjara \\ Central Department of Microbiology, Tribhuvan University \\ Prakash Ghimire \\ Central Department of Microbiology, Tribhuvan University \\ Upendra Thapa Shrestha \\ Central Department of Microbiology, Tribhuvan University
}

\title{
Plasmid Profiling and Occurrence of $\beta$-lactamase Enzymes in Multi-drug Resistant Uropathogenic Escherichia coli in Kathmandu, Nepal
}

\section{Research article}

Keywords: Extended Spectrum $\beta$-lactamases, Amp C, Carbapenemases, Metallo- $\beta$-lactamases, Klebsiella pneumoniae carbapenamase

Posted Date: June 3rd, 2019

DOI: https://doi.org/10.21203/rs.2.10025/v1

License: (c) (i) This work is licensed under a Creative Commons Attribution 4.0 International License. Read Full License 


\section{Abstract}

Background Emergence of Extended Spectrum $\beta$-Lactamases (ESBL) among gram-negative bacteria, predominantly Escherichia coli in Nepal has been alarming. The main objectives of this study were to determine the prevalence of ESBL, ABL (AmpC type $\beta$-Lactamase), MBL (Metallo $\beta$ Lactamase) and KPC (Klebseilla pneumoniae carbapenamase) producing multi-drug resistant uropathogenic E. coli and their correlation with plasmid profiling pattern among the patients suspected of or having urinary tract infection in a tertiary hospital in Kathmandu, Nepal. Methods The mid-stream urine samples were collected from patients suspected of or having urinary tract infections (UTI) and were inoculated in Cystine Lactose electrolyte deficient (CLED) agar. The ESBL E. coli were detected by combined disc diffusion technique using cefotaxime with and without clavulanate. The isolates were screened for ABL by inhibitor-based method using cefoxitin alone and/or with cloxacillin. MBL/KPC were detected using combined-disc tests consisting of meropenem alone and with phenylboronic acid (PBA) or Ethylene diamine tetra acetic acid (EDTA), or both PBA and EDTA. Plasmids were extracted by alkaline lysis method from isolates and profiled on agarose gel electrophoresis. Results Out of total 2,661 urine samples, E. coli were isolated in 64.5\% (507/788), among which $170(33.5 \%)$ were MDR isolates. All MDR isolates were resistant to amoxicillin and third generation cephalosporins but were highly sensitive to imipenem $(94.12 \%, 160 / 170)$, amikacin $(92.94 \%, 158 / 170)$ and nitrofurantoin $(86.47 \%, 147 / 170)$. Among 170 MDR isolates, 78.2\% (133/170) were ESBL, 46.3\% (50/170) were AmpC, 11.2\% (19/170) were MBL and $0.6 \%(1 / 170)$ was KPC producers. Coproduction of $\beta$-Lactamases was detected in $24.12 \%(41 / 170)$ of isolates. E. coli isolates showed one plasmid $(>33.5 \mathrm{~Kb})$ which was unanimously present in all the isolates. Overall, 44 different plasmid profile groups were identified based on the molecular weight and number of plasmids. $\beta$-lactamase producers were relatively resistant to higher number of antibiotics $(\leq 10)$ than nonproducer $(\leq 8)$ and number of plasmids were higher in $\beta$-lactamase producers $(\leq 7)$ than non-producers $(\leq 5)$.

\section{Background}

Antimicrobial resistance is one of the greatest challenges in modern empiric treatment of infectious diseases. For the treatment of infections specially caused by Gram negative bacteria, fluoroquinolones, cephalosporins, $\beta$-lactam and $\beta$-lactamase inhibitors alone or in combination are frequently used. However, resistance to such drugs are the major burden on the developing countries. Among them, prevalence of $\beta$-lactamases producing pathogens are on the rise causing threat to clinical Microbiology [1].

ESBLs are defined as $\beta$-lactamases that are capable of hydrolyzing one or more oxyimino- $\beta$-lactams, such as cefotaxime, ceftazidime and aztreonam, at a rate generally $>10 \%$ of that of benzylpenicillin [2,3]. Since the last two decades, E. coli and other Gram-negative bacteria of Enterobacteriaceae family have emerged as ESBL organisms. ESBLs are globally prevalent, with over 1.5 billion people colonized with ESBLproducing Enterobacteriaceae till date [4].

The selective pressure induced by continuous and uncontrolled use of $\beta$-lactam antibiotics have triggered the emergence of diverse form of mutated novel $\beta$-lactamase enzymes $[5,6]$. Increasingly, E. coli has emerged as prominent bacteria for producing such newer $\beta$-lactamases. They comprise of plasmid-mediated AmpC $\beta$-lactamases (e.g. CMY types), extended-spectrum $\beta$-lactamases (e.g. TEM, SHV, CTX-M types), and carbapenemases (Klebsiella pneumoniae carbapenamase (KPC) types, metallo- $\beta$-lactamases (MBLs) and OXA-types) [7,8]. CMY, CTX-M, and NDM types of $\beta$-lactamases are predominantly responsible for the growing resistance to the $\beta$-lactam antibiotics among E. coli [9].

Co-existence of multiple $\beta$-lactamases in bacterial pathogens pose diagnostic and treatment challenges [10]. ESBL with AmpC production among E. coli often vitiate $\beta$-lactam therapy [11]. As a matter of concern, the development of resistance to the carbapenems evolves, as these drugs are often the ultimate resort for effective treatment against multi-antibiotics resistant and ESBL/AmpC producing Enterobacteriaceae [12] leaving us with potentially toxic drugs, such as polymyxin and colistin [11].

The traits for $\beta$-lactamases; the enzymes hydrolyzing $\beta$-lactam antibiotics, are usually carried in transferable genes. Those genes are usually found on plasmid encoding resistance to aminoglycosides, sulfonamides, tetracyclines and other antibiotics [13]. Those carrying R-plasmids are the most serious problems among antibiotic resistant bacteria because of their propensity to spread rapidly [14] with laboratory evidence of horizontal transfer of multi-antibiotics resistant plasmids among clinical isolates[15]. Thus, the infections caused by bacteria producing $\beta$-lactamases pose serious challenges to clinicians and require immediate attention for more effective diagnostic techniques with newer antibiotics.

Urinary tract infection is one of the most common burdens in the hospitals and particularly affects both sexes at the reproductive age [16]. Although recognized as a most prevalent illnesses in infectious diseases wards in the hospitals, a routine laboratory diagnosis with antibiotic profile and ESBL identification is scarcely done $[3,16]$. In most cases, only basic routine urine microbiological tests are conducted before prescribing the empirical treatment, and this may be even more prominent in non-tertiary hospitals and peripheral health facilities [3].

Prescribing antibiotics without routinely identifying the organisms and their antibiotic profile can contribute to antibiotic resistance including ESBL organisms [17]. Additionally, in Nepal, antibiotics are available over the counter without a prescription from doctors or health care practitioners [18]. Although recognized as a major problem in Nepal similar to other developing nations, scrutinizing such a practice in nearest future is unlikely and is entwined with the local social, cultural and political context. Nevertheless, one way to mitigate the rising antibiotic resistance including ESBL organisms would be to strengthen the central and peripheral laboratories for the routine monitoring of these organisms [3].). 
Several studies in the past have investigated the prevalence of ESBL organisms among inpatients. Studies have shown the varying prevalence of ESBL organisms, for instance the prevalence was 27.7\% in Pokhara [17], 55\% in Kathmandu [19] 64\% in Chitwan [20], 43\% in Children Hospital in Kathmandu in 2018 [21]. Another study reported 35.9\% ESBL in E. coil isolates among outpatients at tertiary care hospital in Kathmandu [22]. However, similar study from Lalitpur district reported 6.8\% ESBL producing isolates [23]. Studies have shown the wide range in prevalence of ESBLs (10 to 64\%) in different Hospitals/settings from various samples. However, there are very few studies which have explored the ESBL organisms amongst the uropathogens from the clinical samples of patients suspected or diagnosed of urinary tract infections. In addition, studies so far have used only phenotypical method to detect and determine the prevalence of ESBL organisms. In our knowledge, there has not been any studies exploring the prevalence of ESBL together with the complete plasmid profile among uropathogens. The main objectives of this study were to determine the prevalence of ESBL, ABL (AmpC type $\beta$-Lactamase), MBL (Metallo $\beta$-Lactamase) and KPC (Klebseilla pneumoniae carbapenamase) producing multi-drug resistant uropathogenic $E$. coli and their correlation with plasmid profiling ( genotyping) pattern among the patients suspected of or having urinary tract infection in a tertiary hospital in Kathmandu, Nepal.

\section{Methods}

A hospital based cross-sectional study was conducted from October 2013 to March 2014 at Kathmandu Model Hospital, Kathmandu, Nepal. A total of 2, 661 non-repetitive mid-stream urine samples were received from out-patient department ( OPD) and Intensive care unit (ICU) during the study period. Urine Samples were obtained in a clean, leak proof container with no visible signs of contamination and were labeled properly with demographic information of patients. The samples from patients with recent history of antibiotics therapy were excluded from this study.

Identification of $E$. coli

Urine samples were cultured on Cystine Lactose electrolyte deficient (CLED) agar by semi-quantitative culture technique [24]. The isolation and identification of Escherichia coli were performed following standard microbiological techniques as described by American Society of Microbiology (ASM) [25].

Antimicrobial susceptibility testing

Antimicrobial susceptibility testing was done by using modified Kirby-Bauer disk diffusion method following the guidelines of Clinical and Laboratory Standards Institute guidelines (CLSI) [26]. The following 16 common antibiotic discs were used: Meropenem(10 4 g), and Amoxycillin $(10 \mu \mathrm{g})$, Cefotaxime $(30 \mu \mathrm{g})$, Cefixime $(30 \mu \mathrm{g})$, Ceftriaxone $(30 \mu \mathrm{g})$, Ceftazidime $(30 \mu \mathrm{g})$, cefoxitin $(30 \mu \mathrm{g})$, Cotrimoxazole $(25 \mu \mathrm{g})$, Nitrofurantoin $(300 \mu \mathrm{g})$,

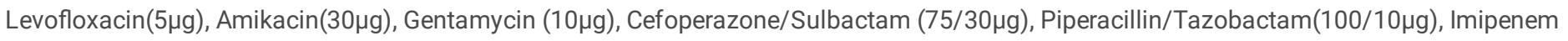
$10 \mu \mathrm{g})$, Doxycycline $(30 \mu \mathrm{g})$. E. coli which were resistant to at least one agent in three or more antibiotic categories were characterized as Multi-drug resistant (MDR) E. coli [27].

Screening and phenotypic confirmation of ESBL, ABL, MBL and KPC

Detection of ESBL

ESBL screening was performed using cefotaxime $(30 \mu \mathrm{g})$, ceftazidime $(30 \mu \mathrm{g})$ or ceftriaxone $(30 \mu \mathrm{g})$ following CLSI guidelines [26]. ESBL production

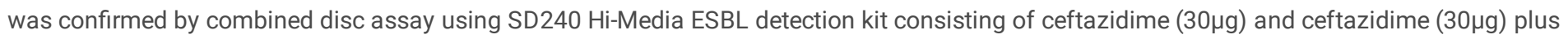
clavulanic acid $(10 \mu \mathrm{g})$.

Detection of $A B L$

MDR isolates were screened for ABL production using Cefoxitin $(30 \mu \mathrm{g})$ with screening cutoffs of $\leq 18$ (i.e. the CLSI susceptible breakpoints) [28] and were further subjected to phenotypic confirmation (Combined Disc Assay) using cefoxitin $(30 \mu \mathrm{g})$ alone and in combination with cloxacillin $(200 \mu \mathrm{g})$. Increment of the zone of inhibition by $\geq 4 \mathrm{~mm}$ was considered as positive result [29].

Detection of MBLs and KPCs

E. coli isolates were considered MBL producers when the inhibitory zone diameters around the Meropenem disc with Ethylene diamine tetra-acetic acid (EDTA) and the Meropenem disc with phenylboronic acid, PBA+EDTA had increased to $\geq 5 \mathrm{~mm}$ as compared to the inhibitory zone diameter of Meropenem disc alone. Similarly, KPC producers among E. coli isolates were considered when the inhibitory zone diameter around the Meropenem disc with PBA and the Meropenem disc with PBA+EDTA had increased to $\geq 5 \mathrm{~mm}$ as compared to the inhibitory zone diameter of Meropenem disc alone [30].

The reference strains, ESBL positive E. coli NCTC 1335, ESBL negative E. coli ATCC 2592, MBL positive E. coli IOM TU 388.1, and MBL negative E. coli ATCC 25922 were included in the study for quality control.

Extraction and profiling of plasmid DNA

Page $3 / 12$ 
Plasmid DNA was extracted by alkaline lysis method [31]. The extracted DNA was separated on $0.8 \%$ agarose gel electrophoresis at $120 \mathrm{~V}$ for 1 hour, stained with SYBR safe stain solution and a photograph of stained gel was taken after exposure on UV trans-illuminator. Reference as super mix plasmid DNA marker (GeNei ${ }^{\mathrm{TM}}$, Genei Laboratories Private Limited, India) was used for the estimation of plasmid sizes. Plasmid profiles were created by grouping strains possessing the same number of plasmid bands and molecular size [32].

\section{Results}

Out of 2,661 urine samples, $29.61 \%$ (788/2661) samples showed significant growth. E. coli was the predominant bacterial species accounting $64.64 \%$ (507/788) of total isolates in which 170 (33.53\%) were multidrug resistant (MDR). All MDR isolates were resistant to amoxicillin and $3^{\text {rd }}$ generation cephalosporins (ceftriaxone, cefotaxime, cefixime and ceftazidime) whereas were highly sensitive to imipenem (94.12\%, 160/170), amikacin $(92.94 \%, 158 / 170)$ and nitrofurantoin $(86.47 \%, 147 / 170)$ (Table 1).

Antibiotic resistant pattern of MDR E. coli showed altogether 18 different resistant phenotypes (Table 2). The isolates seemed to be resistant to number of antimicrobials that ranged from six to 16 of the commonly used antibiotics (Table 2).

B-lactamases production was observed in 121 strains. Out of which, 133 (78.2\%) were ESBL producers, followed by 50 (46.3\%) AmpC, 19 (11.2\%) MBL and $1(0.6 \%)$ KPC producers. The co-production of ESBL and AmpC was observed in $33(19.4 \%)$ isolates, followed by 5 (2.9\%) ESBL and MBL, 2(1.2\%) MBL and AmpC, and 1 (0.6\%) MBL and KPC co-producers (Figure 1).

The $\beta$-lactamase producers were relatively resistant to higher number of categories of antibiotics $(\leq 10)$ than non-producer $(\leq 8)$ and similarly, number of plasmids were higher in $\beta$-lactamase producer $(\leq 7)$ than non-producer isolates $(\leq 5)$ (Table 2$)$. E. coli isolateson plasmid profiling showedthat one plasmid ( $\geq 33.5 \mathrm{~Kb}$ ) was unanimously present in all the isolates. The number of plasmids among the isolates varied from 1 to 7 along with the variable size ranging from $0.8 \mathrm{~kb}$ to $>33.5 \mathrm{~kb}$. Forty-four different plasmid profile groups were obtained based on the pattern of molecular weight and number of plasmids content in isolates. The number of isolates per plasmid profile group varied from 1-20. Maximum number of isolates had two plasmids ((67 (39.41\%)), followed by three plasmids ((29 (17.05\%)), and one plasmid ((20 (11.76\%)). The most frequent molecular weight pattern obtained was $>33.5 \mathrm{~Kb} ; 20$ (11.76\%) followed by $>33.5 ; 19$ (11.17\%). (Table 4).

Non- $\beta$-lactamase producing isolates were found to possess one, two and five plasmids whereas $\beta$-lactamase producers have multiple plasmids. Most of ESBL, AmpC and ESBL/AmpC positive isolates had variable number of plasmids with one plasmid size (>33.5 Kb) in common. $\mathrm{MBL}$ producers and co-producers of MBL with AmpC, ESBL and KPC had few numbers of plasmids, however, all of them contained plasmid size greater or equal to $33.5 \mathrm{~Kb}$ in common. The lower molecular size plasmids showed no significant role in $\beta$-lactamase production. The lowest molecular weight plasmid i.e. $0.8 \mathrm{~Kb}$ was found in non $\beta$-lactamase producing isolates (Table 3).

\section{Discussion}

E. coli is a predominant cause of both community and nosocomial urinary tract infections [33]. The trend of emerging multi-antibiotic resistant $E$. coli among clinical samples raises a major concern for the clinician. The findings of this study show a high level of resistance among $E$. coli against antibiotics with sensitivity to imipenem (94.12\%), amikacin (92.94\%) and nitrofurantoin (86.47\%). Consistent results of resistance have been reported from Saudi Arabia [34], Egypt [35] and India [36]. E. coli isolates from clinical settings showed resistance to nitrofurantoin that ranged from $2.4 \%$ to $6.5 \%$, and to amikacin (2\%) while resistance to imipenem were only $0.3 \%$ [34]. Our findings are consistent with the study from India which showed least resistance to Amikacin (13.9\%) and imipenem (2.3\%) [36]. Many studies have shown that meropenem have greater potency than imipenem by 4-16 folds even in E. coli and other members of Enterobacteriaceae [37,38]. However, contrastingly, this study found higher sensitivity of imipenem (94.12\%) than meropenem (12.35\%). One study from India has shown the consistent findings with our study [39]. The differences with the other studies may be due to the fact that our samples were derived from patients who were suspected or diagnosed with UTI in contrast to other studies which derived samples from various types of patients in different settings.

More than $70 \%$ of the isolates were ESBL producers, nearly half of the isolates were AmpC producers and fewer percent of MBL and KPC producers were found in this study. The continuous exposure of bacteria to a variety of $\beta$-lactams has been well established for the production of $\beta$ lactamases, the most common mechanism of conferring $\beta$-lactams resistance among Enterobacteriaceae[5]. The $\beta$-lactamase enzymes production mediated by both chromosomal and plasmid genes (subject to inducible expression) is a pivotal means of antibiotic resistance. These characteristic features are usually coded on transferable genes [5]. $\beta$-lactamases genes are usually found on plasmid encoding resistance to aminoglycosides, fluroquinolones, sulfonamides, tetracyclines and other antibiotics [40] thus leading to cross resistance. ESBL, AmpC and carbapenemases like MBL and KPC leaves us with limited treatment options. Further, MBL just like ESBL and AmpC, can be transferred between species by plasmids [41].

In Nepal, there were limited studies demonstrating a high level of ESBL producers among which Enterobacteriaceae were 28\% to 67\% [42]. Most of the studies conducted showed the ESBL producers' range as low as $22.3 \%$ to as high as $86.9 \%$. Studies conducted in hospital settings reported 
55\% ESBL produces in Kathmandu [42], 27.7\% in Pokhara [17] and 63.27\% in Kathmandu model hospital [43]. Previous studies from India have reported ESBL productions in uropathogenic E. coli ranging from $18.5 \%$ to $60.7 \%$ [44].

AmpC $\beta$-lactamases are plasmid mediated that hydrolyze all cephalosporins except cefepime and the carbapenems. In AmpC, the inducible chromosomal genes are mobilized as plasmids [45]. In this study, the rate of AmpC detection was 46.3\%. The production of AmpC in our hospital setting is higher compared to other studies that showed $19.8 \%$ over a period of six months at various tertiary care hospitals in India [46], $11.9 \%$ at teaching hospital in Nigeria [47], and 5\% in three major hospitals of Iran [48]. The higher rate of AmpC in this study might be due to use of penicillin, cephalosporins and oxymino- $\beta$-lactams drugs as primary choice of empiric therapy for the infections caused by Gram negative bacteria.

Carbapenems are the ultimate resort for treatment of isolates resistant to penicillin and cephalosporins. Carbapenem resistance due to carbapenemase production was firstly discovered in 1988 in New York, America [49]. In our study, the rate of MBL detection was 11.2\%. Government medical college in Uttarakhand, India reported 15.3\% MBL producing isolates [10] and medical college of South India reported 13.4\% MBL producing E. coli [11] which are almost consistent with this study. MBL producing E. coli were similar across other studies from India (2.87\%), Dubai $(0.3 \%)$ and Nigeria $(41.2 \%)[50,51,52]$. In this study, KPC production was $0.6 \%$ in contrast to a study conducted in Iran which reported the prevalence of KPC to be $1.4 \%$ [51]. This particular difference could have been due to the variation in the settings.

A total of 41 (24.12\%) isolates co-produced $\beta$-lactamase enzymes in this study whereas other studies from our similar settings, with different clinical samples have reported to be 6.2\% [53]. However, a study from Punjab, India showed similar prevalence of 19.04\% [54]. The co-existence of different classes of $\beta$-lactamases in a single bacterial isolate impose diagnostic and treatment challenges with limited available drugs which are potentially toxic that includes polymyxin and colistin [11]. Furthermore, the outcomes for infected patients treated with such drugs remain unknown [55].

E. coli isolateson plasmid profiling showedone plasmid $>33.5 \mathrm{~Kb}$ and was unanimously present in all the isolates. Many of the isolates possessed common plasmids of similar molecular size and these isolates also show same $\beta$-lactamase production. Existence of common plasmid among the isolates implies the spread of resistant plasmid in the community. Plasmids of molecular size ranging from $0.8 \mathrm{~Kb}$ to $>33.5 \mathrm{~Kb}$ were isolated from all the MDR isolates. Contrastingly, plasmid sizes ranging from $0.12 \mathrm{~Kb}$ up to $65 \mathrm{~Kb}$ were reported from West $\mathrm{Africa}(0.12 \mathrm{~Kb}$ to $23 \mathrm{~KB})$, Kathmandu $(2.05 \mathrm{~Kb}$ to $>33.5 \mathrm{~Kb})$ and Nigeria $(11.8 \mathrm{~Kb}$ to $35.5 \mathrm{~Kb})[32,53,56]$.

Different plasmids can co-exist in the same host cell [28]. Based on the antibiotic resistance patterns, the high molecular weight plasmid seemed to consist most of the resistance gene as previous studies have also demonstrated that multi-antibiotic resistance is associated with higher molecular weight plasmids $[57,58]$. Comparing the antibiotic pattern with plasmid profile pattern does not offer much in linking specific antibiotic pattern with specific plasmid profile. This suggests that the genes for resistance to various antibiotic patterns were probably distributed in plasmids of various sizes as well as in the chromosomes.

Conclusions

This study has shown a high prevalence of beta lactamases producing $E$. coli in a tertiary hospital of Kathmandu. This clearly shows the urgency of the emerging resistance. To counteract such an emerging resistance, at first detection of ESBL should be routinely recommended in all tertiary hospital including the peripheral laboratories of Nepal. Second, an antibiotic therapy guideline should be developed to scrutinize the use of antibiotics in the hospitals including the on the counter sale of antibiotics for infections such as UTI. In addition, surveillance of the plasmid and chromosome of $E$. coli is essential as plasmid analysis can be useful to ascertain the evolution and spread of antibiotic resistance among isolates.

\section{Abbreviations}

ABL: AmpC type $\beta$-Lactamase; AST: Antibiotic Susceptibility test; ATCC: American Type Culture Collection; CLED: Cystine Lactose Electrolyte Deficient agar; CLSI: Clinical and Laboratory Standard Institute; EDTA: Ethylene diamine-tetraacetic Acid; ESBL: Extended spectrum $\beta$-lactamase; IPD: Inpatients department; KMH: Kathmandu Model Hospital; KPC: Klebsiella pneumoniae carbapenamase; MBL: Metallo- $\beta$-lactamase; MDR: Multi-drug Resistant; MHA: Mueller Hinton Agar; MSU: Mid-stream Urine; NDM: New Delhi Metallo $\beta$-lactamase; OPD: Out patients department; PBP: Phenyl Boronic Acid; UTI: Urinary Tract Infection; WHO: World Health Organization

\section{Declarations}

Ethical approval and consent

Ethical clearance was taken from institutional review committee (IRC); phect-NEPAL. A copy of information letter and consent form was given to patients to obtain consent before participating in the research and providing sample. In case of illiterate participant, information was provided by reading the consent form in presence of witness.

Consent for publication 
Not applicable

Availability of data and materials

All data pertaining to this study are within the manuscript.

Competing interests

The authors declare that they have no competing interests.

Funding

To conduct this research, no fund was received from any sources.

Authors' contribution

UTS and BS developed the concept of research work. SS and NA conceived and designed the study, collected the samples, carried out research works. MRB, KRR and PG, UTS analyzed the data, and prepared the initial draft of the manuscript. MRB, PG, KRR, BA, and UTS provided oversight for the project. SS, KRR, BA, and UTS revised the subsequent versions of the manuscript. All authors read and approved the final manuscript.

Acknowledgements

The authors would like thank Kantipur College of Medical Science and Kathmandu Model Hospital for providing opportunity to conduct this study. The authors are also grateful to all the patients and technical staffs for their help during the study.

\section{References}

1. Doi Y, Lovleva A, Bonomo RA. The ecology of extended-spectrum b-lactamases (ESBLs) in the developed world. Journal of Travel Medicine, 2017;24(1): S44-S51. doi: 10.1093/jtm/taw102

2. Bush K, Jacoby GA. Updated functional classification of b-lactamases. Antimicrob Agents Chemother 2010; 54:969-76.

3. Raut S, Adhikari B. ESBL and their identification in peripheral laboratories of Nepal. Nepal Med Coll J 2015; 17 (3-4): 176-81.

4. Woerther PL, Burdet C, Chachaty E, Andremont A. Trends in human fecal carriage of extended-spectrum b-lactamases in the community: toward the globalization of CTX-M. Clin Microbiol Rev 2013;26:744-58.

5. Jacoby GA (2009). AmpC $\beta$-lactamases. Clin Microbiol Rev. 22;161-82.

6. Deshmukh DG, Damle AS, Bajaj JK, Bhakre JB. The metallo $\beta$-lactamase producing clinical isolates from the patients of a tertiary care hospital. J Lab Physicians 2011;3(2):93-7.

7. Bush K. Alarming beta-lactamase-mediated resistance in multidrug-resistant Enterobacteriaceae. Curr Opin Microbiol 2010; 13:558-64.

8. Nordmann P, Poirel L, Toleman MA, Walsh TR. Does broad spectrum $\beta$-lactam resistance due to NDM-1 herald the end of the antibiotic era for treatment of infections caused by Gram-negative bacteria? Antimicrob Agents Chemother. 2011; 66:689-92.

9. Pitout JD. Extraintestinal pathogenic Escherichia coli: a combination of virulence with antibiotic resistance. Front Microbiol. 2012; 3:9. doi: 10.3389/fmicb.2012.00009.

10. Rawat V, Singhai M, Verma PK. Detection of different $\beta$-lactamases and their co-existence by using various discs combination methods in clinical isolates of Enterobacteriaceae and Pseudomonas J Lab Physicians. 2013; 5:21-5.

11. Wadekar MD, Anuradha K, Venkatesha D. Phenotypic detection of ESBL and MBL in clinical isolates of Enterobacteriaceae. Int J Curr Res Acad Rev. 2013; 1:89-5.

12. Livermore DM. $\beta$-lactamases in laboratory and clinical resistance. Clin Microbiol rev. 1995; 8: 557-584.

13. Sharma M, Pathak S and Srivastava P. Prevalence and antibiogram of Extended Specturum-ß-lactamase (ESBL) producing Gram negative bacilli and further molecular Characterization of ESBL producing coli and Klebsiella Spp. J Clin \& Diag Res. 2013;7(10): 2173-77.

14. Saeed A, Khatoon H, Ansari FA. Multidrug resistant Gram-negative bacteria in clinical isolates from Karachi. Pak J Pharm Sci. 2009; 22:44-8.

15. Motayo BO, Ogiogwa IJ, Okerentugba PO, Innocent-Adiele HC, Nwanze JC, OnohCC, Okonko IO. Antimicrobial resistance profile of Extraintestinal coli infections in a Southwestern Nigerian City. J Microbiol Res. 2012;2(5):141-4.

16. Pradhan B, Pradhan SB. Prevalence of urinary tract infection and antibiotic susceptibility pattern to urinary pathogens in Kathmandu Medical College and Teaching Hospital, Duwakot. BJHS. 2017;2 (1) 2: 134-37.

17. Raut S, Gokhale S, Adhikari B. Prevalence of extended spectrum beta-lactamases among Escherichia coli and Klebsiella isolates in Manipal Teaching Hospital, Pokhara, Nepal. J Microbiol and Infect Dis. 2015;5(2):69-75.

18. Raut S, Adhikari B. Global leadership against antimicrobial resistance ought to include developing Countries. Lancet Infect Dis. 2016; 16(7): 775. 
19. Sharma AR, Bhatta DR, Shrestha J, Banjara MR. Antimicrobial susceptibility pattern of Escherichia coli isolated from urinary tract infected patients attending Bir Hospital. Nep J Sci and Tech. 2013;14(1):177-184.

20. Shrestha, A, Manandhar S, Pokharel P, Panthi P, Chaudhry DK. "Prevalence of extended spectrum beta-lactamase (ESBL) producing multidrug resistance Gram-negative isolates causing urinary tract infection”. EC Microbiology. 2016; 5: 749-755.

21. Sharma KR, Bhandari P, Adhikari N, Tripathi P, Khanal S, Tiwari BR. Extended spectrum ß-lactamase (ESBL) producing multi-drug resistant urinary pathogens in a children hospital from Nepal. Kathmandu Univ Med J (KUMS) 2018;16 (62): 151-55.

22. Nepal K, Pant ND, Neupane B, Belbase A, Baidhaya R, Shrestha RK, Lekhak B, Bhatta DR, Jha B. Extended spectrum beta-lactamase and metallo-beta-lactamase producing coli and Klebsiella pneumoniae isolated from different clinical samples in a tertiary care- hospital in Kathmandu. Ann Clin Microbiol Antimicrob. 2017;19 (16): 62. doi: 10.1186/s12941-017-0236-7.

23. Rai S, Pant ND, Bhandari R, Giri A, Parajuli R, Aryal M, Amatya J, Sharma VK. Ampc and Extended spectrum beta-lactamase production urinary isolates from a tertiary care hospital in Lalitpur, Nepal. BMC Res Notes. 2017; 10 (1): 467.doi:10.1186/s3104-017-2784-5.

24. Cheesbrough M. District laboratory practice in tropical countries, part II. $2^{\text {nd }}$ New York: Cambridge university press; 2006. P. $112-3$.

25. Isenberg HD. Clinical Microbiology Procedures Handbook. 2nd ed. Washington, D.C: ASM Press 2004.

26. Clinical Laboratory Standard Institute (CLSI): Performance standards for antimicrobial susceptibility testing; Twenty second informational supplement document. Wayne, PA: CLSI: 2012; M100-S20.

27. Magiorakos AP, Srinivasan A, Carey RB, Carmeli Y, Falagas ME, Giske CG, et al. Multidrug-resistant, extensively drug-resistant and pan drug resistant bacteria: an international expert proposal for interim standard definitions for acquired resistance. Clin Microbiol. Infect. 2012; 18:268-81.

28. Polsfuss S, Bloemberg GV, Giger J, Meyer V, Böttger EC, Hombach M. Practical approach for reliable detection of AmpC beta-lactamaseproducing Enterobacteriaceae. J Clinic Microbiol. 2011;49(8):2798-2803. doi:10.1128/JCM.00404-11.

29. Tan TY, Yong-Ng LS, He J, Koh TH, Hsu LY. Evaluation of screening methods to detect plasmid mediated AmpC in Escherichia coli, Klebsiella pneumoniae and Proteus mirabilis. Antimicrob Agents Chemother. 2009; 53:146-9.

30. Tsakris A, Poulou A, Pournaras S, Voulgari E, Vrioni G, Digalaki KT, et al. A simple phenotypic method for the differentiation of metallo- $\beta$ lactamases and class A KPC carbapenemases in Enterobacteriaceae clinical isolates. Antimicrob Agents Chemother 2010; 65:1664-71.

31. Sambrook J, Fritsch EF, Maniatis T. Molecular cloning: a laboratory manual 2nd ed. Cold Spring Harbor Laboratory Press, Cold Spring Harbor, NY. 1989.

32. Daini OA, Adesemowo A. Antimicrobial susceptibility patterns and R-plasmids of clinical strains of Escherichia Coli. Aust J Basic Appl Sci. 2008; 2:397-400.

33. Foxman B. The epidemiology of urinary tract infection. Nat Rev Urol. 2010;7(12):653-660. doi: 10.1038/nrurol.2010.190.

34. Al-Tawfiq JA. Increasing antibiotic resistance among isolates of Escherichia coli recovered from inpatients and outpatients in a Saudi Arabian hospital. Infect Control Hosp Epidemiol 2006;27: 748-53.

35. Salem MM, Muharram M, Alhosiny IM (2010). Distribution of classes 1 and 2 integrons among multi drug resistant coli isolated from hospitalized patients with urinary tract infection in Cairo, Egypt. Aus J Basic and Appl Sci. 2010; 4:398-407.

36. Christopher AF, Hora S, Ali Z. Investigation of plasmid profile, antibiotic susceptibility pattern, multiple antibiotic resistance index calculation of Escherichia coli isolates obtained from different human clinical specimens at tertiary care hospital in Bareilly-India. Ann Trop Med Public health. 2013; 6:285-9.

37. Zhanel GG, Simor AE, Vercaigne L, Mandell L. Imipenem and meropenem: Comparison of in vitro activity, pharmacokinetics, clinical trials and adverse effects. Can J Infect 1998; 9:215-28.

38. Piller CM, Torres MK, Brown NP, Shah D and Sahm DF. In vitro activity of Doripenem, a Carbapenem for the treatment of challenging infections caused by Gram-negative Bacteria, against recent clinical isolates from the United States. Antimicrob Agents Chemother. 2008; 52:4388-99.

39. Padmini SB, Appalaraju B. Extended spectrum $\beta$-lactamases in urinary isolates of coli and Klebsiella pneumoniae, prevalence and susceptibility pattern in tertiary care hospital. Ind J Med Microbiol. 2004; 223:172- 4.

40. Khajuria A, Praharaj AK, Kumar M, Grover N. Emergence of Escherichia coli, co-producing NDM-1 and OXA-48 carbapenemases, in urinary isolates, at a tertiary care centre at central India. J Clin Diagn Res. 2014;8: DC01-4.

41. Hammer DA, Dongol S, Anderson TP, Wong JS, Werno AM, Murdoch DR. High prevalence of extended-spectrum beta-lactamase-producing Enterobacteriaceae in Nepal. Int J Antimicrob Agents. 2007;30(5):471-472. doi: 10.1016/j.ijantimicag.2007.07.004.

42. Baral P, Neupane S, Marasini BP, Ghimire KR, Lekhak B, Shrestha B. High prevalence of multidrug resistance in bacterial uropathogens from Kathmandu, Nepal. BMC Res Notes. 2012,5: 38-10.1186/1756-0500-5-38.

43. Shrestha S, Mali NM, Tiwari KB, Adhikari N, Shrestha UT, Basnyat SR. Antibiogram and plasmid profiling of clinical multidrug resistant Escherichia coli. Journal of institute of Medicine. 2014;35(2):21-26

44. Bora A, Ahmed GU, Hazarika NK. Antibiotic resistance pattern and prevalence of ESBL producing Escherichia coli isolates in urinary tract infection from a tertiary care hospital of Guwahati, Assam. IJBPAS. 2012;1(11): 1659-1668.

Page 7/12 
45. Manoharan A, Sugumar M, Kumar A, Jose H, Mathai D, Khilnani GC, et al. Phenotypic and molecular characterization of AmpC $\beta$ lactamases among Escherichia coli, Klebsiella spp and Enterobacter spp from five Indian medical centers. Indian J Med Res. 2012; 135:359-64.

46. Sasirekha B. Prevalence of ESBL, AmpC $\beta$ - lactamases and MRSA among uropathogens and its antibiogram. EXCLI Journal. 2013; 12:81-8.

47. YusufAH, Arzai M, Haruna AA, Sharif, Getso MI. Detection of multi drug resistant bacteria in major hospitals in Kano, North-West, Nigeria. Braz J Microbiol 2014;45(3): 791-8.

48. Shayan S, Bokaeian M. Detection of ESBL- and AmpC-producing coli isolates from urinary tract infections. Adv Biomed Res. 2015 ; 4:220. doi:10.4103/2277-9175.166643.

49. Zavascki AP, Barth AL, Gonçalves AL, Moro AL, Fernandes JF, Martins AF, et al. The influence of metallo-beta-lactamase production on mortality in nosocomial Pseudomonas aeruginosa J Antimicrob Chemother. 2006; 58:387-92.

50. Pandya NP, Prajapati SP, Mehta SJ, Kikani KM, Joshi PJ. Evaluation of various methods for detection of metallo-betalactamase (MBL) production in Gram negative bacilli. Int J Biol Med Res. 2011;2(3):775-7.

51. Moayednia R, Shokri D, Mobasherizadeh S, Baradaran A, Fatemi SM, Merrikhi A. Frequency assessment of $\beta$-lactamase enzymes in Escherichia coli and Klebsiella isolates in patients with urinary tract infection. Journal of Research in Medical Sciences: J Isfahan Uni Med Sci. 2014;19(1): S41-S45.

52. Enwuru NV, Enwuru CA, Ogbonnia SO, Adepoju-Bello. Metallo-beta-lactamase production by Escherichia coli and Klebsiella species isolated from hospital and community subjects in Lagos, Nigeria. Nature and Science. 2011;9(11):1-5.

53. Shrestha B, Shrestha S, Mishra SK, Kattel HP, Tada T, Ohara H, et al. Phenotypic characterization of multidrug-resistant Escherichia coli with special reference to extended-spectrum-beta-lactamases and metallo-beta-lactamases in a tertiary care center. J Nepal Med Assoc 2015;53(198):89-95.

54. Oberoi L, Singh N, Sharma P, Aggarwal A. ESBL, MBL, AmpC $\beta$-lactamases producing superbugs - Havoc in the intensive care units of Punjab, India. J Clin Diag Res. 2013;7(1):70-3.

55. Urban C, Bradford PA, Tuckman M, Segal-Maurer S, Wegbeh W, Grenner L, et al. Carbapenem-resistant Escherichia coli harboring Klebsiella pneumoniae carbapenemase-beta- Lactamases associated with long-term care facilities. Clin Infect Dis. 2008;46(1):127-30.

56. Motayo BO, Akinduti PA, Adeyakinu FA, Okerentugba PO, Nwanze JC, Onoh CC, et al. Antibiogram and plasmid profiling of carbapenemase and extended spectrum beta-lactamase (ESBL) producing Escherichia coli and Klebsiella pneumoniae in Abeokuta, South western, Nigeria. Afr Health Sci. 2013;13(4):1091-7.

57. McPherson P, Gealt M. Isolation of indigenous wastewater bacterial strains capable of mobilizing plasmid pBR325. Appl Environ Microbiol. 1986; 51:904-9.

58. Zulkifli Y, Alitheen NB, Raha AR, Yeap SK, Marlina, Son R, Nishibuchi M. Antibiotic resistance and plasmid profiling of Vibrio parahaemolyticus isolated from cockles in Padang, Indonesia. Inter Food Res J. 2009; 16:53-58.

\section{Tables}

Table 1 Antibiotic susceptibility pattern of MDR E. coli isolates $(n=170)$ 


\begin{tabular}{lll}
\hline Antibiotics used & Sensitive (\%) & Resistant (\%) \\
\hline First line of antibiotics & & \\
Amoxycillin & 0 & $170(100)$ \\
Cefixime & 0 & $170(100)$ \\
Cefotaxime & 0 & $170(100)$ \\
Ceftriaxone & 0 & $170(100)$ \\
Ciprofloxacin & $7(4.12)$ & $163(95.88)$ \\
Cotrimoxazole & $24(14.12)$ & $146(85.88)$ \\
Levofloxacin & $24(14.12)$ & $146(85.88)$ \\
Nitrofurantoin & $147(86.47)$ & $23(13.53)$ \\
Second line of antibiotics & & \\
Amikacin & $158(92.94)$ & $12(7.05)$ \\
Cefoperazone/Sulbactam & $91(53.53)$ & $79(46.47)$ \\
Ceftazidime & 0 & $170(100)$ \\
Doxycycline & $61(35.88)$ & $109(64.12)$ \\
Gentamycin & $146(85.88)$ & $24(14.12)$ \\
Imipenem & $160(94.12)$ & $10(5.88)$ \\
Meropenem & $21(12.35)$ & $149(87.65)$ \\
Piperacillin/Tazobactam & $108(63.53)$ & $62(36.47)$ \\
\hline
\end{tabular}

Table 2 Antibiotic resistance pattern of clinical isolates of MDR E. coli isolates

\begin{tabular}{lll}
\hline stance phenotype (RP) $\quad$ Resistance Pattern & No. of isolates showing the pattern \% $(\mathrm{n}=170)$
\end{tabular}

\begin{tabular}{|c|c|}
\hline AmxCtxCtrCfmCazCipLevCotCfsPitMrpDox & $26(15.29 \%)$ \\
\hline AmxCtxCtrCfmCazCipLevCotMrpDox & $25(14.71 \%)$ \\
\hline AmxCtxCtrCfmCazCipLevCotNitCfsPitMrpDox & $14(8.24 \%)$ \\
\hline AmxCtxCtrCfmCazCipLevCotMrp & $14(8.24 \%)$ \\
\hline AmxCtxCtrCfmCazCipLevCotDox & $11(6.47 \%)$ \\
\hline AmxCtxCtrCfmCazCipLevMrp & $10(5.88)$ \\
\hline AmxCtxCtrCfmCazCipLevCotCfsMrp & $9(5.29 \%)$ \\
\hline AmxCtxCtrCfmCazCipMrp & $8(4.71 \%)$ \\
\hline AmxCtxCtrCfmCazCipLevCotGenCfsMrpDox & $7(4.12 \%)$ \\
\hline AmxCtxCtrCfmCazCot & $7(4.12 \%)$ \\
\hline AmxCtxCtrCfmCazCipLevCotAkGenCfsPitMrplpmDox & $7(4.12 \%)$ \\
\hline AmxCtxCtrCfmCazCipCotMrpDox & $6(3.53 \%)$ \\
\hline AmxCtxCtrCfmCazCipLevCfsPitMrpDox & $6(3.53 \%)$ \\
\hline AmxCtxCtrCfmCazCipLevCotNitMrp & $5(2.94 \%)$ \\
\hline AmxCtxCtrCfmCazCipCot & $4(2.35 \%)$ \\
\hline AmxCtxCtrCfmCazCipLevCotGenMrp & $4(2.35 \%)$ \\
\hline AmxCtxCtrCfmCazCipLevCotAkGenCfsPitMrpDox & $4(2.35 \%)$ \\
\hline AmxCtxCtrCfmCazCipLevCotNitAkGenCfsPitMrplpmDox & $3(1.76 \%)$ \\
\hline
\end{tabular}

Note: Amx-Amoxycillin, Ctx-Cefotaxime, Ctr-Ceftriaxone, Cfm- Cefixime, Caz-Ceftazidime, Cot-Cotrimoxazole,Nit-Nitrofurantoin, Lev-Levofloxacin, Ak-Amikacin, Gen- Gentamycin, Cfs-Cefoperazone/Sulbactam, Pit-Piperacillin/Tazobactam, Mrp-Meropenem, Ipm-Imipenem, Dox-Doxycycline. 
Table 3 Resistance to different class of antibiotics among $\beta$-lactamase producer and non-producer MDR isolates

\begin{tabular}{|c|c|c|c|c|c|c|c|c|c|}
\hline & $\begin{array}{l}\text { No. } \\
\text { of } \\
\text { strain }\end{array}$ & $\begin{array}{r}\text { ESBL } \\
(n=95)\end{array}$ & $\begin{array}{l}\text { AmpC } \\
(n=15)\end{array}$ & $\begin{array}{l}\text { MBL } \\
(n=11)\end{array}$ & $\begin{array}{l}\text { ESBL+ } \\
\text { AmpC } \\
(n=33)\end{array}$ & $\begin{array}{l}\text { ESBL+MBL } \\
(n=5)\end{array}$ & $\begin{array}{l}M B L+A m p C \\
(n=2)\end{array}$ & $\begin{array}{l}\text { MBL+KPC } \\
(n=1)\end{array}$ & $\begin{array}{l}\text { Non- } \\
\text { producer } \\
(n=8)\end{array}$ \\
\hline AmxCtxCtrCfmCazCot & 7 & 7 & -- & -- & - & -- & -- & -- & -- \\
\hline AmxCtxCtrCfmCazCipLevMrp & 22 & 7 & 1 & -- & -- & -- & -- & -- & 2 \\
\hline AmxCtxCtrCfmCazCipMrp & & 7 & -- & -- & 1 & -- & -- & -- & -- \\
\hline AmxCtxCtrCfmCazCipLevCotMrp & 25 & 14 & -- & -- & -- & -- & -- & -- & -- \\
\hline AmxCtxCtrCfmCazCipLevCotDox & & 9 & -- & -- & 2 & -- & -- & -- & -- \\
\hline AmxCtxCtrCfmCazCipLevCotMrpDox & & 18 & -- & -- & 7 & -- & -- & -- & 1 \\
\hline AmxCtxCtrCfmCazCipLevCotCfsMrp & & 6 & -- & -- & 1 & -- & -- & -- & 2 \\
\hline AmxCtxCtrCfmCazCipCotMrpDox & 49 & 5 & -- & -- & 1 & -- & -- & -- & -- \\
\hline AmxCtxCtrCfmCazCipLevCotNitMrp & & 4 & -- & -- & 1 & -- & -- & -- & -- \\
\hline AmxCtxCtrCfmCazCipLevCotGenMrp & & 3 & -- & -- & 1 & -- & -- & -- & -- \\
\hline AmxCtxCtrCfmCazCipLevCotCfsPitMrpDox & 33 & 4 & 5 & -- & 9 & 3 & 2 & -- & 3 \\
\hline AmxCtxCtrCfmCazCipLevCotGenCfsMrpDox & & 5 & 1 & -- & 1 & -- & -- & -- & -- \\
\hline AmxCtxCtrCfmCazCipLevCotAkGenCfsPitMrpDox & 28 & -- & 1 & 1 & 2 & -- & -- & -- & -- \\
\hline AmxCtxCtrCfmCazCipLevCotNitCfsPitMrpDox & & 3 & 4 & 2 & 4 & 1 & -- & -- & -- \\
\hline AmxCtxCtrCfmCazCipLevCotAkGenCfsPitMrplpmDox & & -- & -- & 7 & -- & -- & -- & -- & -- \\
\hline AmxCtxCtrCfmCazCipLevCotNitAkGenCfsPitMrplpmDox & 3 & -- & -- & 1 & -- & 1 & -- & 1 & -- \\
\hline
\end{tabular}

Amx-Amoxycillin, Ctx-Cefotaxime, Ctr-Ceftriaxone, Cfm- Cefixime, Caz-Ceftazidime, Cot-Cotrimoxazole,Nit-Nitrofurantoin, Lev-Levofloxacin, AkAmikacin, Gen- Gentamycin,Cfs-Cefoperazone/Sulbactam, Pit-Piperacillin/Tazobactam,Mrp-Meropenem, Ipm-Imipenem, Dox-Doxycycline

Table 4 Plasmid profile of MDR E. coliisolates 


\begin{tabular}{|c|c|c|c|c|c|}
\hline No. of plasmid & Type & Molecular Weight (Kb) & $\begin{array}{l}\text { Plasmid } \\
\text { profile }\end{array}$ & $\begin{array}{l}\text { No. of isolates } \\
\text { Showing Profile (\%) }\end{array}$ & Total number $\quad(\%)$ \\
\hline 1 & 1a & $>33.5$ & 1 & $20(11.76)$ & $20(11.76)$ \\
\hline \multirow[t]{7}{*}{2} & $2 a$ & $>33.5,33.5$ & 2 & $19(11.17)$ & 67 \\
\hline & $2 b$ & $>33.5(2)$ & 3 & $12(7.1)$ & $(39.41)$ \\
\hline & $2 c$ & $>33.5,15.0$ & 4 & $10(5.88)$ & \\
\hline & $2 d$ & $>33.5,9.4$ & 5 & $9(5.29)$ & \\
\hline & $2 e$ & $>33.5,10.1$ & 6 & $8(4.71)$ & \\
\hline & $2 f$ & $>33.5,6.0$ & 7 & $5(2.94)$ & \\
\hline & $2 g$ & $>33.5,4.8$ & 8 & $4(2.35)$ & \\
\hline \multirow[t]{10}{*}{3} & $3 a$ & $>33.5,15.0,2.0$ & 9 & $6(3.53)$ & 29 \\
\hline & $3 b$ & $>33.5(2), 3.0$ & 10 & $5(2.94)$ & (17.05) \\
\hline & $3 c$ & $>33.5,6.7,2.4$ & 11 & $4(2.35)$ & \\
\hline & $3 d$ & $>33.5,14.0,1.5$ & 12 & $3(1.76)$ & \\
\hline & $3 e$ & $>33.5(2), 33.5$ & 13 & $2(1.17)$ & \\
\hline & $3 f$ & $>33.5,14.0,9.0$ & 14 & $2(1.17)$ & \\
\hline & $3 g$ & $>33.5(2), 2.2$ & 15 & $2(1.17)$ & \\
\hline & $3 \mathrm{~h}$ & $>33.5,33.5,2.1$ & 16 & $2(1.17)$ & \\
\hline & $3 i$ & $>33.5,9.0,4.0$ & 17 & $2(1.17)$ & \\
\hline & $3 j$ & $>33.5,2.0,1.5$ & 18 & $1(0.58)$ & \\
\hline \multirow[t]{9}{*}{4} & $4 a$ & $>33.5,15.0,4.0,2.0$ & 19 & $9(5.29)$ & 29 \\
\hline & $4 \mathrm{~b}$ & $>33.5,33.5,4.8,4.0$ & 20 & $6(3.53)$ & (17.05) \\
\hline & $4 c$ & $>33.5,15.0,4.0,2.5$ & 21 & $3(1.76)$ & \\
\hline & $4 d$ & $>33.5,15.0,7.0,5.0$ & 22 & $3(1.76)$ & \\
\hline & $4 e$ & $>33.5,33.5,6.3,3.1$ & 23 & $3(1.76)$ & \\
\hline & $4 f$ & $>33.5(2), 2.6,2.0$ & 24 & $1(0.58)$ & \\
\hline & $4 \mathrm{~g}$ & $>33.5,33.5,14.8,11.8$ & 25 & $1(0.58)$ & \\
\hline & $4 \mathrm{~h}$ & $>33.5,33.5,2.0,1.0$ & 26 & $2(1.17)$ & \\
\hline & $4 i$ & $>33.5(2), 33.5,4.4$ & 27 & $1(0.58)$ & \\
\hline \multirow[t]{7}{*}{5} & $5 a$ & $>33.5(2), 5.0,3.1,2.4$ & 28 & $3(1.76)$ & 9 \\
\hline & $5 b$ & $>33.5(3), 33.5,1.2$ & 29 & $1(0.58)$ & $(5.29)$ \\
\hline & $5 c$ & $>33.5,33.5,2.0,1.5,1.0$ & 30 & $1(0.58)$ & \\
\hline & $5 d$ & $>33.5,33.5,3.1,2.0,1.6$ & 31 & $1(0.58)$ & \\
\hline & $5 e$ & $>33.5(2), 33.5,3.0,2.0$ & 32 & $1(0.58)$ & \\
\hline & $5 f$ & $33.5,10.0,7.4,4.0,3.0$ & 33 & $1(0.58)$ & \\
\hline & $5 g$ & $>33.5,15.0,5.0,4.4,0.8$ & 34 & $1(0.58)$ & \\
\hline \multirow[t]{9}{*}{6} & $6 a$ & $>33.5,10.6,4.0,3.0,1.5,1.2$ & 35 & $4(2.35)$ & \\
\hline & $6 b$ & $>33.5(2), 6.0,3.0,2.0,1.5$ & 36 & $3(1.76)$ & \\
\hline & $6 c$ & $>33.5(2), 12.7,9.0,5.0,2.5$ & 37 & $1(0.58)$ & \\
\hline & $6 d$ & $>33.5(2), 5.0,4.8,2.4,2.1$ & 38 & $1(0.58)$ & \\
\hline & $6 e$ & $>33.5(3), 33.5,3.0,1.0$ & 39 & $1(0.58)$ & \\
\hline & $6 f$ & $>33.5,12.0,5.5,2.5,1.9,1.2$ & 40 & $1(0.58)$ & \\
\hline & $6 \mathrm{~g}$ & $>33.5,33.5,4.0,3.0,2.0,1.6$ & 41 & $1(0.58)$ & \\
\hline & $6 \mathrm{~h}$ & $>33.5,33.5,7.0,5.0,4.0,2.0$ & 42 & $2(1.17)$ & \\
\hline & $6 i$ & $>33.5,33.5,12.7,15.0,3.0,1.5$ & 43 & $1(0.58)$ & \\
\hline 7 & $7 a$ & $>33.5,33.5,9.4,3.0,2 \cdot 2,2.0,1.0$ & 44 & $1(0.58)$ & $1(0.58)$ \\
\hline
\end{tabular}

* Parentheses ( ) represents times of mol. weight of plasmid repeated among the isolates

Table 5: Plasmid profiling in relation to $\beta$-lactamase production in MDR E. coli isolates

\begin{tabular}{|c|c|c|c|c|c|c|c|c|c|c|}
\hline $\begin{array}{l}\text { Plasmid } \\
\text { Number }\end{array}$ & Molecular weight & $\begin{array}{l}\text { No. of } \\
\text { isolate }\end{array}$ & ESBL & AmpC & MBL & $\begin{array}{l}\text { ESBL/ } \\
\text { AmpC }\end{array}$ & $\begin{array}{l}\text { ESBL/ } \\
\text { MBL }\end{array}$ & $\begin{array}{l}\mathrm{MBL} / \\
\mathrm{AmpC}\end{array}$ & $\begin{array}{l}\mathrm{MBL} / \\
\mathrm{KPC}\end{array}$ & $\begin{array}{l}\text { Non- } \\
\text { producer }\end{array}$ \\
\hline 1 & $>33.5$ & 20 & 13 & 2 & - & 3 & - & - & - & 2 \\
\hline 2 & $>33.5,33.5,15.0,10.1,9.4,6.0,4.8$ & 67 & 32 & 6 & 7 & 14 & - & 2 & 1 & 5 \\
\hline 3 & $>33.5,33.5,15.0,14.0,9.0,6.7,4.0,3.0,2.4,2.2,2.1,2.0,1.5$ & 29 & 16 & 4 & 2 & 6 & 1 & - & - & - \\
\hline 4 & $\begin{array}{l}>33 \cdot 5,33 \cdot 5,15 \cdot 0,14 \cdot 8,11 \cdot 8,7 \cdot 0,6 \cdot 3,5 \cdot 0,4 \cdot 8,4 \cdot 4 \\
4.0,3 \cdot 1,2 \cdot 5,2 \cdot 6,2 \cdot 0,1.0\end{array}$ & 29 & 21 & - & 1 & 5 & 2 & - & - & - \\
\hline 5 & $\begin{array}{l}>33 \cdot 5,33 \cdot 5,15 \cdot 0,10 \cdot 0,7 \cdot 4,5 \cdot 0,4 \cdot 4,4 \cdot 0,3 \cdot 8,3.1, \\
3 \cdot 0,2 \cdot 4,1 \cdot 6,1 \cdot 5,1 \cdot 2,1 \cdot 0,0.8\end{array}$ & 9 & 5 & 1 & 1 & 1 & - & - & - & 1 \\
\hline 6 & $\begin{array}{l}>33.5,33.5,12.7,10.6,9.0,7.0,6.0,5.0,4.8,4.0,3.0, \\
2.5,2 \cdot 4,2 \cdot 1,2.0,1.9,1.6,1.5,1.2,1.0\end{array}$ & 15 & 7 & 2 & - & 4 & 2 & - & - & - \\
\hline 7 & $>33.5,33.5,9.4,3.0,2.2,2.0,1.0$ & 1 & 1 & - & - & - & - & - & - & - \\
\hline Total iso & & 170 & 95 & 15 & 11 & 33 & 5 & 2 & 1 & 8 \\
\hline
\end{tabular}




\section{Figures}

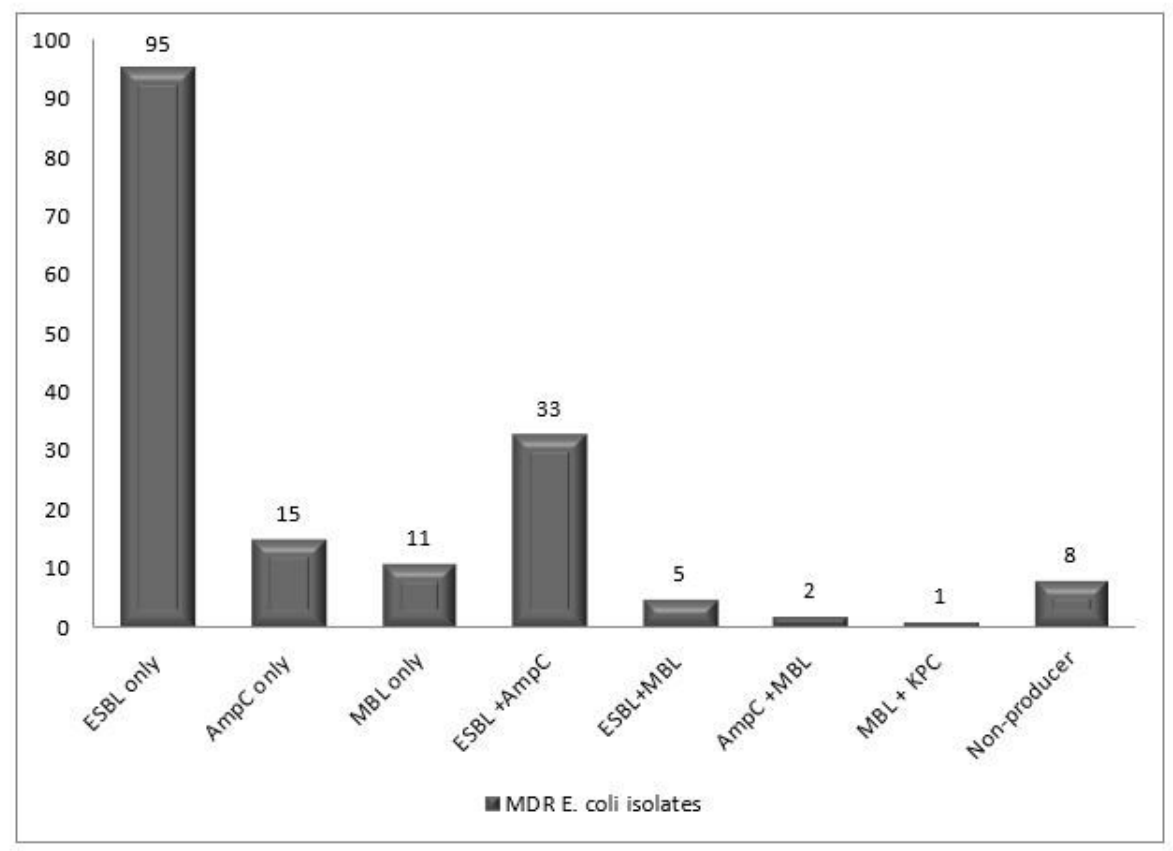

Figure 1

Distribution of different $\beta$-Lactamases among MDR E. coli isolates

\section{Supplementary Files}

This is a list of supplementary files associated with this preprint. Click to download.

- supplement1.docx

- supplement2.docx

- supplement3.docx

- supplement4.docx

- supplement5.docx 